\title{
Pengaruh Epoch pada Akurasi menggunakan Convolutional Neural Network untuk Klasifikasi fashion dan Furniture
}

\author{
Muhammad Wasil $1^{*}$, Harianto², Fathurrahman ${ }^{3}$ \\ 1,2Program Studi Teknik Informatika, Universitas Hamzanwadi \\ 3Program Studi Sistem Informasi, Universitas Hamzanwadi \\ *wasilmuhammad2109@gmail.com
}

\begin{abstract}
Abstrak
Fashion dan furniture menjadi kebutuhan untuk setiap individu. Pemilihan fashion terkadang juga bisa menjadi penilaian orang lain terhadap karakter yang dimiliki tiap individu. Begitupun pemilihan furniture juga bisa menggambarkan identitas dari tiap individu. Namun fashion dan furniture memiliki berbagai macam model, untuk itu dibutuhkan teknologi informasi yang bisa membedakan antara model a dan model b. Klasifikasi adalah salah satu model yang mengelompokkan berdasarkan kriteria yang sama. Penggunaan klasifikasi haruslah didukung dengan metode yang tepat dan penggunaan epoch agar akurasi yang dihasilkan dapat maksimal. Metode Convolutional Neural Network (CNN) adalah metode yang sangat tepat untuk klasifikasi gambar karena terdapat banyak arsitektur yang bisa digunakan.Hasil penelitian ini menunjukkan bahwa akurasi terbaik pada furniture $=94.18 \%$ dengan penggunaan epoch $=500$, dan fashion $=99.15 \%$ dengan penggunaan epoch $=1500$
\end{abstract}

Kata kunci: CNN, fashion, furniture, epoch

\begin{abstract}
Fashion dan furniture menjadi kebutuhan untuk setiap individu. Pemilihan fashion terkadang juga bisa menjadi penilaian orang lain terhadap karakter yang dimiliki tiap individu. Begitupun pemilihan furniture juga bisa menggambarkan identitas dari tiap individu. Namun fashion dan furniture memiliki berbagai macam model, untuk itu dibutuhkan teknologi informasi yang bisa membedakan antara model a dan model b. Klasifikasi adalah salah satu model yang mengelompokkan berdasarkan kriteria yang sama. Penggunaan klasifikasi haruslah didukung dengan metode yang tepat dan penggunaan epoch agar akurasi yang dihasilkan dapat maksimal. Metode Convolutional Neural Network (CNN) adalah metode yang sangat tepat untuk klasifikasi gambar karena terdapat banyak arsitektur yang bisa digunakan.Hasil penelitian ini menunjukkan bahwa akurasi terbaik pada furniture $=94.18 \%$ dengan penggunaan epoch $=500$, dan fashion $=99.15 \%$ dengan penggunaan epoch $=1500$.
\end{abstract}

Keywords: CNN, fashion, furniture, epoch

\section{Pendahuluan}

Fashion merupakan hal yang wajib diperhatikan oleh setiap orang. Dikalangan kaum muda terdapat berbagai macam fashion yang bisa dipilih sesuai dengan kebutuhan dan selera nya. Pemilihan fashion bisa menjadi penilaian tersendiri dari orang lain terhadap karakter yang dimiliki masing-masing individu. Dalam memenuhi kebutuhan akan busana, kadang manusia tidak semuanya membuat sendiri, tetapi dapat membeli busana yang sudah jadi, atau dipesan pada seseorang atau lembaga usaha 
jasa pembuatan busana[1]. Dahulu fashion merupakan kebutuhan secondary namun seiring berjalan nya waktu dan pergantian zaman, fashion sudah menjadi kebutuhan yang sangat dikehendaki dan bisa dipilih sesuai dengan selera individu. Fashion pada zaman ini sudah banyak mengalami perubahan terutama pada model nya.

Furniture secara umum adalah benda pakai yang dapat dipindahkan, berguna bagi kegiatan/aktivitas manusia, mulai dari duduk, tidur, bekerja, makan, memasak, bermain dan sebagainya, yang memberi kenyamanan dan keindahan bagi pemakainya[2]. Setiap rumah pasti memiliki banyak furniture salah satunya adalah sofa. Sofa menjadi barang yang sangat penting untuk dimiliki. Sofa memiliki berbagai macam model untuk pemilihan sofa tergantung dari selera si pembeli.

Epoch menandakan satu siklus algoritma machine learning 'belajar' dari data set training yang ingin diproses saja atau dikenal dengan istilah mini batch. Dengan penggunaan mini batch mesin tidak belajar dari keseluruhan data tapi belajar dari batch yang telah ditentukan. Satu epoch berarti sebuah algoritma machine learning telah 'belajar' dari data training secara keseluruhan. Dalan jaringan saraf tiruan, proses pembelajaran yang berulang-ulang bertujuan untuk mencapai konvergensi nilai bobot[3]. Nilai epoch secara pasti tidak diketahui sehingga penggunaan epoch bergantung pada jumlah data yang digunakan.

Banyaknya data fashion dan furniture yang sudah dibuat menjadi sebuah dataset dapat dimanfaatkan untuk melakukan penelitian pencarian akurasi terbaik menggunakan Machine Learning dan Deep Learning. Hal ini dapat menghasilkan berbagai macam tingkat akurasi bergantung pada penggunaan metode dan arsitektur yang digunakan. Deep Learning dapat memecahkan masalah sentral dalam pembelajaran representasi dengan memperkenalkan representasi yang diekspresikan dalam bentuk representasi lain yang lebih sederhana. Pembelajaran yang mendalam memungkinkan komputer untuk membangun konsep kompleks dari konsep yang lebih sederhana [4].

Klasifikasi dapat digunakan pada beberapa bidang seperti machine learning,deep learning dan artficial intelgence.Trend pada deep learning telah meningkat pada 10 tahun terakhir. Maka dari itu penggunaan klasifikasi pada deep learning diharapkan dapat menemukan akurasi/hasil yang tinggi.Proses klasifikasi tidak lepas dari data yang digunakan, baik berupa teks atau gambar(image processing). Pada klasifikasi terdapat penggunaan epoch(iterasi) yang digunakan untuk melakukan proses perulangan klasifikasi gambar untuk mencari var loss dan accuracy yang digunakan. Accuracy yang 
dihasilkan bisa saja berbeda bergantung pada epoch yang digunakan. Dalam garis besar fungsi epoch untuk pembelajaran mesin, terkadang penggunaan banyak epoch dapat meningkatkan accuracy yang dicari namun bisa juga penggunaan banyak epoch accuracy yang dihasilkan akan stabil(tidak meningkat) oleh sebab itu perlunya penggunaan epoch yang tepat untuk pembelajaran mesin agar akurasi yang didapat maksimal. Selain penggunaan epoch.

\section{Tinjauan Pustaka}

\subsection{Penelitian Terkait}

Penelitian sebelumnya [5] tujuan penelitian ini yaitu mencari pendekatan alternatif di mana melatih deep learning network untuk memprediksi waktu pelaksanaan untuk bagianbagian dari jaringan deep learning network. Hasil dari model ini dapat digunakan untuk memprediksi waktu eksekusi untuk neural network secara lengkap.

Penelitian sebelumnya [6] tujuan penelitian ini yaitu Memecahkan masalah penjadwalan tingkat pembelajaran dan mengendalikan lokalitas pencarian. Hasil percobaan awal menunjukkan bahwa LOG-BP berkinerja lebih baik; yaitu, ketika diperlukan, tingkat pembelajaran menurun secara eksponensial dan jarak antara kromosom, yang menunjukkan lokalitas pencarian, juga menurun secara eksponensial.
Penelitian sebelumnya [7] tujuan penelitian ini yaitu klasifikasi image-net menggunakan alex net dan epoch yang telah ditentukan. Hasil percobaan memiliki akurasi tertinggi sesuai dengan penggunaan batch $32768=0.585$

Penelitian sebelumnya [8] tujuan penelitian ini yaitu klasifikasi multi-label mode fashion dengan pembelajaran dari data noisy dengan minimal human supervision. Hasil tertinggi dalam percobaan yaitu Improve model (pretrain) = 78.83 .

Penelitian sebelumnya [9] tujuan penelitian ini yaitu mengusulkan jaringan fashion yang dipandu pengetahuan yang bekerja untuk memecahkan masalah analisis mode visual, mis., lokalisasi mode landmark dan klasifikasi kategori pakaian.. Hasil berdasarkan kategori yaitu : top-3=90.99, top-5=95.78 dan hasil berdasarkan Atribut yaitu : top-3= 51.53 , top$5=60.95$.

Penelitian sebelumnya [10] tujuan penelitian ini yaitu Melakukan klasifikasi SNea hanya dari gambar pengamatan single-epoch menggunakan CNN. Hasil dari penelitian single epoch, w/o redshift $=0.958$, multi epoch,, w/o redshift $=$ 0.995 .

Penelitian sebelumnya [11] tujuan penelitian ini yaitu klasifikasi gambar yang mencerminkan struktur hirarki kategori pakaian menggunakan metode CNN. Hasil dari penelitian in memiliki rata-rata akurasi 91.33 . 
Infotek : Jurnal Informatika dan Teknologi

Vol. 5 No. 1, Januari 2022

Hal. 53-61

e-ISSN 2614-8773

Link : https://dx.doi.org/10.29408/ jit.v5i1.4393

\subsection{Landasan Teori}

Convolutional Neural Network adalah salah satu algoritma deep learning yang berfokus pada image,text. Dari focus tersebut bisa menghasilkan akurasi,kecepatan yang bias diketahui. Pada CNN banyak arsitektur yang bias digunakan untuk pengoptimalan pembelajaran mesin maka dari itu diperlukan arsitektur yang tepat untuk mendapatkan hasil yang diinginkan.

\section{Metode Penelitian}

Klasifikasi secara umum adalah pengelompokan atas dasar kriteria yang sama. Krteria tersebut meliputi jenis, ciri dan kategrori yang sama. Banyak penelitian telah dilakukan untuk proses klasifikasi namun pada penelitian ini di fokuskan pada pencarian penggunaan epoch untuk mencapai akurasi tertinggi. Jika akursi tinggi maka klasifikasi yang dihasilkan akan semakin bagus.

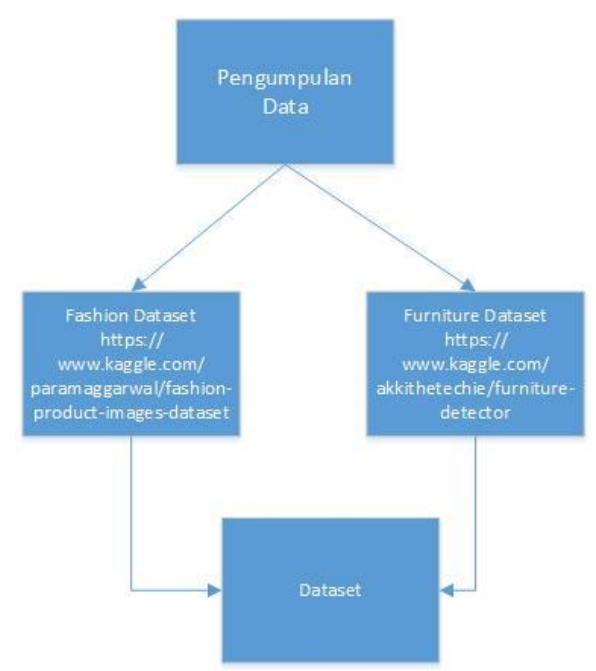

Gambar 1. Alur pengumpulan data
Alur pengumpulan data dapat dilihat pada gambar 1. Data diambil dari website www.kaggle.com dan format data tersebut adalah .jpg. untuk detail pengambilan bisa dilihat pada gambar 1. Data yang telah didownload dijadikan dataset sebanyak 8255 dengan pembagian fashion $=4231$ sedangkan furniture $=4024$

Tabel 1. Label furniture

\begin{tabular}{|l|l|l|}
\hline No & \multicolumn{1}{|c|}{ Furniture } & \multicolumn{1}{c|}{ Jumlah } \\
\hline 1 & Bed & 900 \\
\hline 2 & Chair & 900 \\
\hline 3 & Sofa & 900 \\
\hline 4 & Swivlechair & 900 \\
\hline 5 & Table & 424 \\
\hline
\end{tabular}

Tabel 1 menunjukkan label yang ada pada furniture. Terdapat 5 label yaitu bed, chair, sofa, swivlevhair, dan table. Contoh gambar dari dataset dapat dilihat pada gambar 2 .

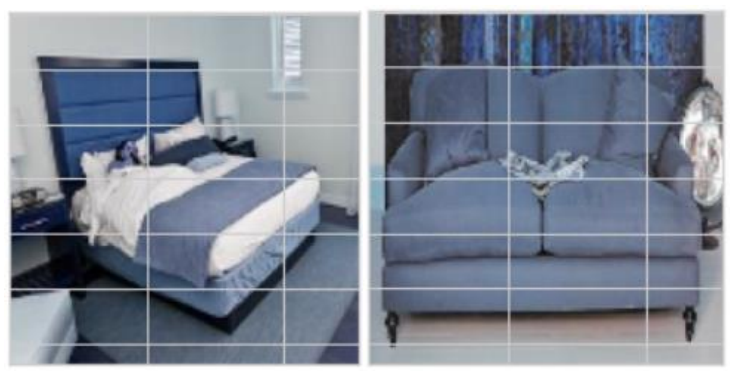

Gambar 2. contoh bed dan sofa

Tabel 2. Label fashion

\begin{tabular}{|l|l|l|}
\hline No & Fashion & Jumlah \\
\hline 1 & Accessories & 1001 \\
\hline 2 & Apparel & 1036 \\
\hline 3 & Footwear & 1013 \\
\hline 4 & Personal Care & 1181 \\
\hline
\end{tabular}


Infotek : Jurnal Informatika dan Teknologi

Vol. 5 No. 1, Januari 2022

Hal. 53-61

e-ISSN 2614-8773

DOI : 10.29408/jit.v5i1.4393

Link : https://dx.doi.org/10.29408/ jit.v5i1.4393

Tabel 2 menunjukkan label yang ada pada fashion. Terdapat 4 label yaitu Accessories, apparel, footwear, personal care. Contoh gambar dari dataset dapat dilihat pada gambar 3 .

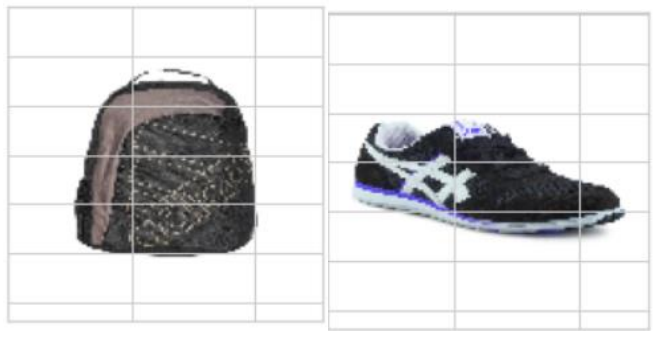

Gambar 3. Contoh accessories dan footwear

\subsection{Tahapan Penelitian}

Penelitian ini bertujuan untuk menentukan penggunaan epoch dengan arsitektur CNN yang telah ditentukan. Tahapan-tahapan pada penelitian ini sebagai berikut:

1. Pengumpulan data

Pengumpulan data yaitu proses pencarian data yang sesuai dan juga dibutuhkan dalam penelitian.

2. Pengolahan data

Data yang sudah dikumpulkan kemudian dilakukan proses pengolahan data.

Pengolahan dengan memberi label pada data dan penyamaan ukuran untuk mempermudah pembentukan metode/model.

3. Metode yang diusulkan

Menggambarkan diagram/alur yang diusulkan dan arsitektur metode CNN. Arsitektur meliputi layer, maxpolling, flatten, dense, activation, dan juga penggunaan epoch yang digunakan.

4. Implementasi model

Penjelasan tentang implementasi pada model yang digunakan

5. Evaluasi hasil

Evaluasi hasil digunakan untuk membandingkan eksperimen yang telah digunakan dengan arsitektur yang berbeda. Dari perbandingan ini dicari akurasi tertinggi.

\section{Hasil dan Pembahasan}

Prosedur penelitian dimulai dari pembagian class pada dataset dan dilakukan proses preprocessing. Setelah itu data diubah menjadi dimensi yang telah ditentukan dan selanjutnya memasukkan kedalam arsitektur CNN. Arsitektur CNN dapat dilihat di gambar 5. Arsitektur CNN dimulai dari proses input gambar, data input diproses pada lapisan konvlusi menggunakan max_polling dan fungsi ReLU. Output pada lapisan konvlusi pertama dijadikan sebagai input pada proses konvlusi kedua, begitu juga seterusnya. Hasil dari proses konvlusi akan di kumpulkan dan diproses pada lapisan Flatten(fully connected). Setelah dataset dimasukkan sesuai dengan arsitektur kemudian dilakukan beberapa percobaan pada data fashion dan furniture dengan menggunakan $500,1000,1500$ epoch. Akurasi terbaik yang didapat yaitu furniture $=92.99 \%$ dengan 
menggunakan epoch=1500, dan fashion = 99.15\% dengan menggunakan epoch 1500 .

Penggunaan epoch dimaksudkan untuk memaksimalkan data yang ingin diproses pada pembelajaran mesin yang telah ditentukan di mini batch.

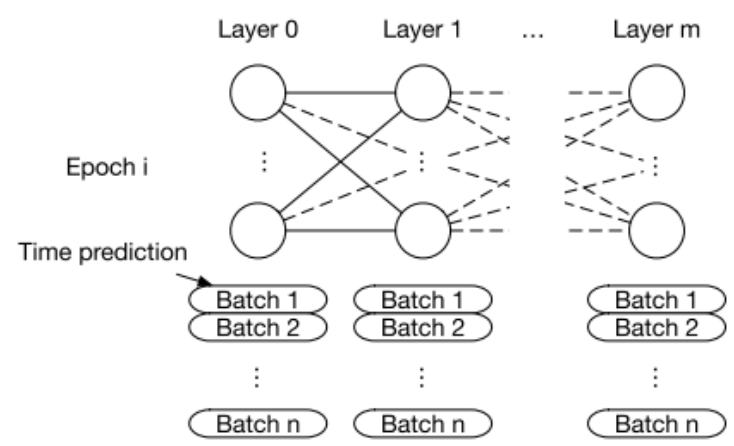

Gambar 4. prediksi waktu full epoch [5]

Pada gambar 4 menjelaskan tentang keterkaitan antara epoch dan batch size untuk prediksi waktu. Prediksi waktu juga dilihat berdasarkan VGA(GPU) yang digunakan.

\begin{tabular}{|c|c|c|}
\hline Layer (type) & Output shape & Param \# \\
\hline conv2d_1 (Conv2D) & (None, $128,128,32$ ) & 2432 \\
\hline max_pooling2d_1 (MaxPooling2 & (None, $64,64,32$ ) & $\theta$ \\
\hline Conv2d_2 (Conv2D) & (None, $64,64,64$ ) & 18496 \\
\hline max_pooling2d_2 (Maxpooling2 & (None, $32,32,64$ ) & $\theta$ \\
\hline Conv2d_3 (Conv2D) & (None, $32,32,96$ ) & 55392 \\
\hline max_pooling2d_3 (MaxPooling2 & (None, $16,16,96$ ) & $\theta$ \\
\hline Conv2d_4 (Conv2D) & (None, 16, 16, 96) & 83040 \\
\hline max_pooling2d_4 (Maxpooling2 & (None, $8,8,96$ ) & $\theta$ \\
\hline flatten_1 (Flatten) & (None, 6144) & $\theta$ \\
\hline dense_1 (Dense) & (None, 512) & 3146240 \\
\hline activation_1 (Activation) & (None, 512) & $\theta$ \\
\hline $\begin{array}{l}\text { dense_2 (Dense) } \\
====================== \\
\text { Total params: } 3,308,678 \\
\text { Trainable params }: 3,308,678 \\
\text { Non-trainable params: } \theta\end{array}$ & $\begin{array}{l}\text { (None, 6) } \\
================\end{array}$ & $\begin{array}{c}3078 \\
======\end{array}$ \\
\hline
\end{tabular}

\section{Gambar 5. Arsitektur CNN}

Penggunaan epoch pada proses klasifikasi dapat meningkatkan akurasi. Epoch berfungsi sebagai perulangan dan sebagai pembelajaran untuk mesin. Sederhana nya semakin banyak epoch yang digunakan semakin baik juga akurasi yang didapat. Namun didalam data set terdapat maksimal akurasi yang bisa didapat. Akurasi klasifikasi furniture dan fashion bisa dilihat pada table 3. Arsitektur CNN yang digunakan pada gambar 5 .

Tabel 3.akurasi berdasarkan epoch

\begin{tabular}{|c|l|l|l|l|}
\hline Kategori & Epoch & Dimensi & Akurasi & $\begin{array}{c}\text { Data } \\
\text { loss }\end{array}$ \\
\hline \multirow{3}{*}{ Fashion } & 500 & $128 \times 128$ & $98.16 \%$ & $2 \%$ \\
\cline { 2 - 5 } & 1000 & $128 \times 128$ & $98.56 \%$ & $1 \%$ \\
\cline { 2 - 5 } & 1500 & $128 \times 128$ & $99.15 \%$ & $3 \%$ \\
\cline { 2 - 5 } & Rerata & $98.62 \%$ & $1.66 \%$ \\
\hline
\end{tabular}

Pada kategori fashion dapat dilihat bahwa akurasi yang didapatkan meningkat seiring bertambahnya epoch yang digunakan. Peningkatan berkisar antara 0.4-0.6. hal tersebut karena mesin memerlukan perulangan untuk proses pembelajaran pada dataset sehingga mendapat akurasi yang maksimal. Rata-rata akurasi yang didapat adalah $98.62 \%$ dengan rincian akurasi tertinggi terdapat di epoch $1500=99.15 \%$.

(a)

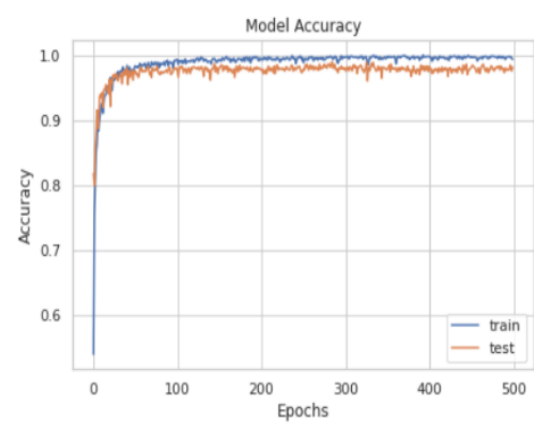

(b) 


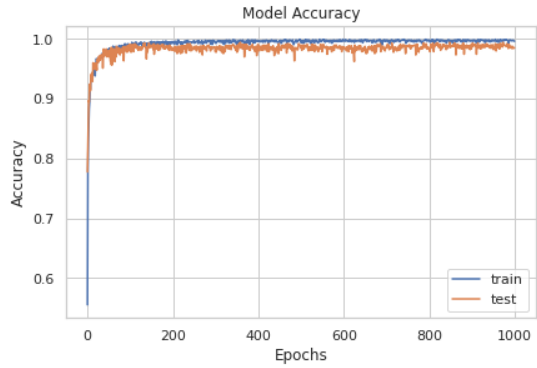

(c)

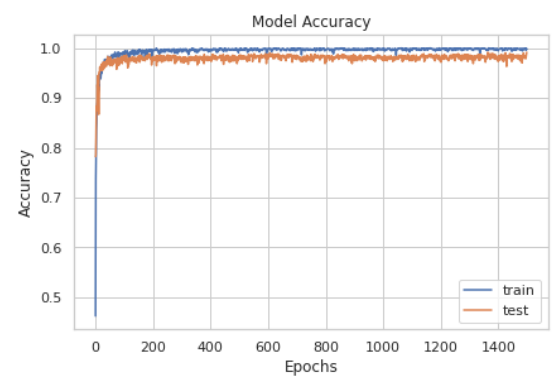

Gambar 6. Accuracy fashion dari penggunaan epoch (a) 500, (b) 1000, (c) 1500

Pada gambar 6 dapat dilihat bahwa peningkatan akurasi fashion dimulai dari epoch $0-50$, untuk epoch selanjutnya akurasi tidak mengalami penaikan atau penurunan yang signifikan.

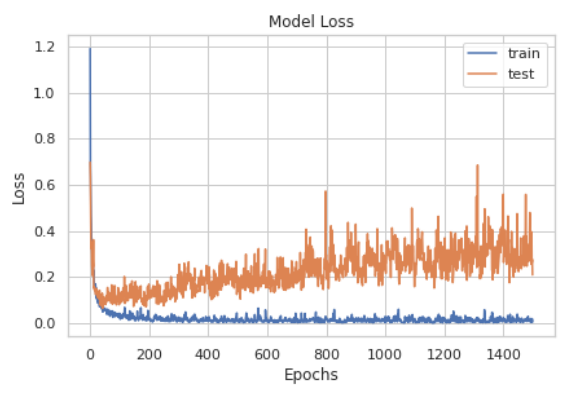

Gambar 7. Model loss fashion

Pada kategori fashion data uji di model loss mengalami penaikan 0.1-0.2 dari awal hanya 0.1. kenaikan tertinggi ada di epoch 1300 dengan data loss sebanyak 0.6 , pada epoch selanjutnya data loss mengalami penaikan dan berakhir di 0.2. untuk data loss spesifik bisa dilihat pada gambar 7 .

Tabel 4. Akurasi furniture

\begin{tabular}{|l|l|l|l|l|}
\hline Kategori & Epoch & Dimensi & Akurasi & $\begin{array}{l}\text { Data } \\
\text { loss }\end{array}$ \\
\hline \multirow{3}{*}{ Furniture } & 500 & $128 \times 128$ & $94.18 \%$ & $3 \%$ \\
\cline { 2 - 5 } & 1000 & $128 \times 128$ & $93.29 \%$ & $5 \%$ \\
\cline { 2 - 5 } & 1500 & $128 \times 128$ & $92.99 \%$ & $7 \%$ \\
\cline { 2 - 5 } & Rerata & $93.48 \%$ & $3.7 \%$ \\
\hline
\end{tabular}

Pada kategori fashion akurasi tertinggi yang didapat yaitu ketika menggunakan epoch 500 dengan akurasi $94.18 \%$ dan total akurasi yang didapat adalah 93.48\%. Akurasi furniture dapat dilihat pada rabel 4 .

(a)

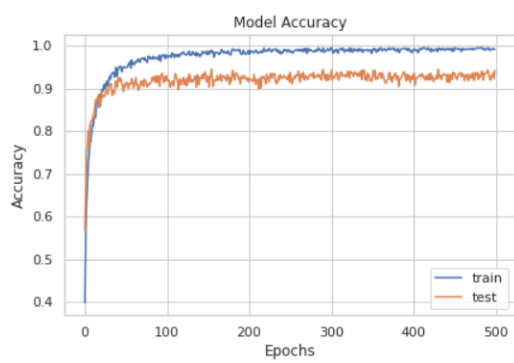

(b)

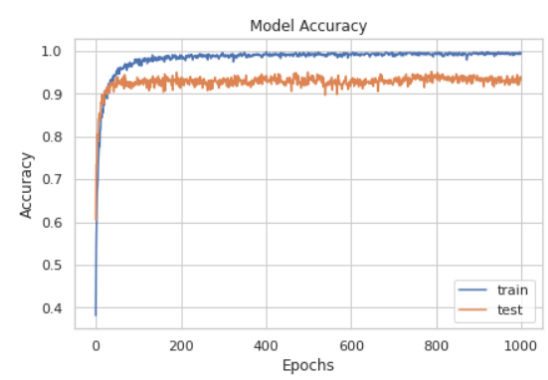

(c) 


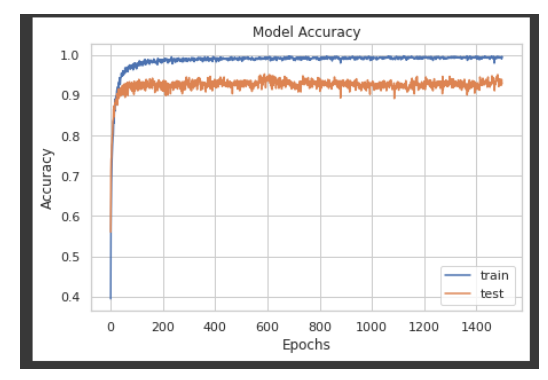

Gambar 8. Accuracy furniture

Pada gambar 8 dapat dilihat akurasi furniture pada data uji dan data pelatihan dengan penggunaan epoch 500-1500

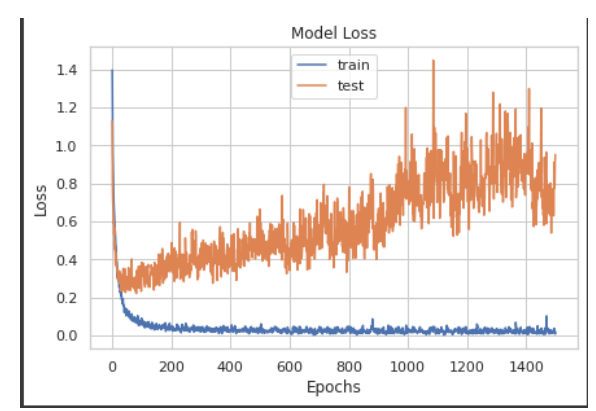

Gambar 9. Model loss furniture

pada kategori furniture data uji mengalami kenaikan 0.5-0.6. penaikan paling tinggi ada pada epoch 1100 setelah itu data loss mengalami penurunan dan berakhir di 0.9. untuk data loss spesifik bisa dilihat pada gambar 9 .

\section{Kesimpulan}

Berdasarkan hasil penelitian mengunakan software google colabs dan Bahasa pemrograman python menggunakan metode CNN hasil yang diperoleh dari ke-dua kategori diatas $90 \%$ yang menunjukkan bahwa penguunaan epoch sangat bepengaruh terhadap akurasi yang dihasilkan.Penggunaan epoch berkisar 500-1500. Selain itu penggunaan minibatch juga berpengaruh untuk gambar yang ingin diproses Dari penelitian ini juga bisa menjadi bahan pertimbangan untuk penelitian selanjutnya dengan menggunakan epoch,arsitektur, dan jumlah data yang sama.

\section{Daftar Pustaka}

[1] A. A. Riyanto, "Sejarah Dan Perkembangan Mode Busana," 2005.

[2] C. Candra, A. Santosa, and M. T. Rizqy, "Perancangan Mebel Multifungsi untuk ' Daily Treats ' Surabaya," J. Intra, vol. 5, no. 2, pp. 322-331, 2017.

[3] M. S. Wibawa, "Pengaruh Fungsi Aktivasi, Optimisasi dan Jumlah Epoch Terhadap Performa Jaringan Saraf Tiruan," J. Sist. dan Inform., vol. 11, no. 2, pp. 167-174, 2017, doi: 10.13140/RG.2.2.21139.94241.

[4] A. Bengio, Yoshua, Goodfellow.ian, Courville, "Deep learning," Nature, vol. 29, no. 7553, pp. 1-73, 2015.

[5] D. Justus, J. Brennan, S. Bonner, and A. S. McGough, "Predicting the Computational Cost of Deep Learning Models," Proc. - 2018 IEEE Int. Conf. Big Data, Big Data 2018, pp. 3873-3882, 2019, doi: 10.1109/BigData.2018.8622396.

[6] Y. Kanada, "Optimizing neural-network learning rate by using a genetic algorithm with per-epoch mutations," Proc. Int. Jt. Conf. Neural Networks, vol. 2016-Octob, no. March, pp. 1472-1479, 2016, doi: 10.1109/IJCNN.2016.7727372.

[7] Y. You, Z. Zhang, C. J. Hsieh, J. Demmel, and $\mathrm{K}$. Keutzer, "ImageNet training in minutes," ACM Int. Conf. Proceeding Ser., no. September, 2018, doi: 10.1145/3225058.3225069.

[8] N. Inoue, E. Simo-Serra, T. Yamasaki, and H. Ishikawa, "Multi-label Fashion Image Classification with Minimal Human 
Supervision," Proc. - 2017 IEEE Int. Conf. Comput. Vis. Work. ICCVW 2017, vol. 2018-Janua, pp. 2261-2267, 2017, doi: 10.1109/ICCVW.2017.265.

[9] W. Wang, Y. Xu, J. Shen, and S. C. Zhu, "Attentive Fashion Grammar Network for Fashion Landmark Detection and Clothing Category Classification," Proc. IEEE Comput. Soc. Conf. Comput. Vis. Pattern Recognit., pp. 4271-4280, 2018, doi: 10.1109/CVPR.2018.00449.

[10] A. Kimura, I. Takahashi, M. Tanaka, N. Yasuda, N. Ueda, and N. Yoshida, "Single-Epoch Supernova Classification with Deep Convolutional Neural Networks," Proc. - IEEE 37th Int. Conf. Distrib. Comput. Syst. Work. ICDCSW 2017, pp. 354-359, 2017, doi: 10.1109/ICDCSW.2017.47.

[11] Y. Seo and K. shik Shin, "Hierarchical convolutional neural networks for fashion image classification," Expert Syst. Appl., vol. 116, pp. 328-339, 2019, doi: 10.1016/j.eswa.2018.09.022.

[12] Sudianto Aris, "Penerapan Website Sebagai Sarana Promosi Wisata Budaya pada Kabupaten Lombok Timur," Infotek J. Inform. dan Teknol., vol. 1Sudianto, no. 1, pp. 11-17, 2018.

[13] A. Sudianto and H. Ahmadi, "Rancang Bangun Sistem Informasi Penjualan Sparepart Motor Pada Bengkel Vinensi Motor Berbasis Web Guna Meningkatkan Penjualan dan Promosi Produk Pendahuluan Vinensi sepeda motor motor," Infotek J. Inform. dan Teknol., vol. 3, no. 2, pp. 32-39, 2020.

[14] A. Sudianto and J. Sugiantara, "Website as Foundation Information Media under the auspices of Nahdlatul Wathan," J. Phys. Conf. Ser., vol. 1539, no. 1, pp. 3-8, 2020, doi: 10.1088/1742$6596 / 1539 / 1 / 012024$

[15] S. M. Sudianto Aris, "Penerapan Sistem Informasi Geografis (GIS) dalam Pemetaan Kerajinan Kain Tenun dan Gerabah untuk Meningkatkan Potensi Kerajinan di Kabupaten Lombok Timur," Infotek J. Inform. dan Teknol. J. Inform. dan Teknol., vol. 1, no. 2, pp. 64-71, 2018. 